\title{
RISK ESTIMATION AND DECISION-MAKING IN MANAGEMENT (IN SELECTED AREAS OF SCIENCE)
}

\author{
TADEUSZ GALANC ${ }^{1}$, WIKTOR KOŁWZAN ${ }^{2}$, JERZY PIERONEK ${ }^{3 *}$, \\ AGNIESZKA SKOWRONEK-GRĄDZIEL ${ }^{2}$ \\ ${ }^{1}$ College of Management „Edukacja”, Krakowska 56-62, 50-425 Wrocław, Poland \\ ${ }^{2}$ Department of Management, General Tadeusz Kościuszko \\ Military University of Land Forces in Wrocław, Czajkowskiego 109, 51-150 Wrocław, Poland \\ ${ }^{3}$ Faculty of Computer Science and Management, Wrocław University of Science and Technology, \\ Łukasiewicza 5, 50-371 Wrocław, Poland
}

\begin{abstract}
Risk is a category that is inseparably connected with uncertainty and probability, which means that the nature of risk as a category of science is complex, and the concept of risk is very difficult to define by one conceptual system of modern science. Due to the above, the main research hypothesis of the work is oriented to the assumption that the complexity of the risk category is determined by the diversity (variety) of reality, as a result of which in science there is currently no uniform methodology for risk assessment and estimation. As a result, the main goal of the article is to describe the research area based on selected representative methods of risk estimation and logical decision-making schemes, as well as to systematise the knowledge about the methodology used in them. In the article, the authors illustrate risk estimation with examples developed by themselves and quoted from various fields of science, differing from one another in formal terms in quantitative and qualitative (numerical and content-verbally) dimensions. Strategic risk, risk of fraction estimation, Bayesian risk, Bayesian methods for estimation of population distribution parameters, risk of econometric model assessment, interest rate risk, banking risk, and adverse event as a measure of risk are here addressed. The article also focuses on the problem of risk estimation in terms of the theory of fractals. The work is to have not only cognitive but also practical meaning. The created source of knowledge should prove helpful for decision-makers in the area of management since effective process management requires the expertise of risk estimation in various dimensions and using various mathematical tools.
\end{abstract}

Keywords: risk estimation methods, risk categories, decision making, management

${ }^{*}$ Corresponding author, email address jerzy.pieronek@pwr.edu.pl Received 13 September 2019, accepted 28 April 2020 


\section{Introduction}

The risk itself in making decisions is in principle not much important for a decisionmaker ${ }^{1}$, as it happens wherever indeterminacy occurs. And yet, in principle, most of our life decisions are directly related to situations not fully defined. The problem is to estimate the risk, i.e., to express it in the form of a numerical or content (qualitative) value. Scientists have written volumes of studies about the risk, and yet the discourse about risk continues $[1,2,6,20]$. Thus, what is the essence of risk?

The answers to the following questions are essential: whether the risk in terms of importance is significant or irrelevant (important or not important), large or small in numerical terms, in other words, whether it is presented qualitatively or quantitatively ${ }^{2}$. The risk of qualitative nature has its quantitative diversity. The problem is methodologically very complicated in this area of risk estimation. The methodology is represented in the form of human behaviours, such as emotions, cultural and moral patterns, politics, a degree of civilization, and religion. Some of these diversity categories are expressed in the form of value systems. Axiology deals with them. This risk category seems to dominate its quantitative side in everyday life. However, in both cases, their measurability is the key issue. Therefore, even from the methodological point of view, a fundamental question arises what quantitative risk is and how to measure it effectively, and,

\footnotetext{
${ }^{1}$ The decision-making process is largely automatic, determined by habits and other unconscious factors. In their work, the authors deal with the dimension of rational decisions in which it is difficult to capture and assess the risk of their implementation.

${ }^{2}$ The authors believe that recognising risk in a quantitative form, i.e. quantitative metrics, is generally easier than expressing it in a qualitative dimension. Comparison of values expressed by culturally different societies raises concern since each of these communities operates with different qualitative measures in relation to one another, which means different axiological systems (in a conceptual sense). In general, the problem here is the that of mutual understanding and, above all, understanding in the dimension of tolerance. Understanding content is one of the basic acts of human language ([14], p. 5-8), which consequently leads to different behaviours, and thereby making a decision (a behaviour is also a decision). Tolerance is a secondary value in relation to understanding human behaviour. Different modern democracies, especially those establishing norms of so-called correctness expressed in the entire spectrum of human behaviours, should know and then remember about it. Europe has experienced this recently in the empirical dimension. A general question arises, whether such mass-scale meetings of mentally and culturally different communities are accidental or perhaps someone manages this process, but for what purpose and how to empirically control it for the good of Europe and, to a large extent, humanity? Is it not the evil side of the concept of globalism, the globalism that is something perfect in the humanitarian sense, what matters here? Resources, i.e. money, are needed to realise it, and no-one gives it away for free, except humanitarian institutions which receive these funds from the donations of citizens of nations, in other words, according to the principle: you have received for free, give it to others. From the economic point of view, this is the proverbial drop in the ocean of needs of the poor part of humanity. Thus, what principle guides the decision makers of globalism? Do they intend to distribute goods to the poor, even though in economics nothing is given away for free? What do they want to get in exchange for it? The risk can be identified with scientific measures, but it has its objective dimension, the dimension of nature, and it must be understood in this sense.
} 
in turn, what metrics (measures) should be used concerning various categories of qualitative risk. The question, therefore, is so crucial, since risk concerns man globally, and human mentality has both a quantitative and qualitative dimension, that is a unity of a dual nature ${ }^{3}$. It is worth referring to methodological issues in this place. It must be clearly emphasised that it is not the methodology that specifies the use of one or other method and tools for the analysis of the problem under investigation, but this is exactly the opposite process. Methods and research tools created within particular sciences, mainly logic and mathematics, physics, biology, and psychology together form a picture of the methodology of science, its specific language that unites science ${ }^{4}$.

Taking advantage of the achievements of the queen of science - mathematics, some quantitative volumes, such as fragments of the economy, financial markets, can be measured quite effectively ([15], p. 117, 118). It is more difficult to capture the qualitative risk in patterns, diagrams, and other similar structures. This is because the qualitative dimension of the human mentality manifests itself externally, as mentioned above, through religion, customs, tradition, a family pattern, and thus through the systems expressed by unknown (actually, not fully understood) explicitly qualitative metrics. The abovementioned dimension of human behaviour is dealt with in such sciences as sociology, psychology, and linguistics (the role of the language structure in communication between people in the sense of individual and social-collective communication). In general, it is also the domain of axiology $y^{5}$. There is a category of measures on the borderline of the quantitative approach to risk and its expression in a qualitative manner, extensively developed in recent decades, which refers to the issue of work valuation, i.e. its measurement [11]. Thus, a risk category is in a sense the isomorphic diversity of the reality that surrounds us, and therefore it refers to the statement that the risk has the

\footnotetext{
${ }^{3}$ The anatomical structure of our brain is such that one hemisphere is responsible for the number and syntactic (operational) structures, and the other one for the content (quality, meaning). The literature on this subject is extremely rich and one of the representative positions is [9], since it contains significant anatomical and symbolic contents related to the processing of information by the human brain.

${ }^{4}$ For example, the first statistical test for studying the conformity of distributions was created in 1900 , not by the methodology of science, but by Karl Pearson, as a part of mathematical statistics, and only now is used in statistical test methodology, in practice of testing statistical hypotheses.

${ }^{5}$ Axiology is located within the humanities and, as the author of cybernetics Norbert Wiener said in his time, the humanities constitute a barren soil for practicing mathematics. However, since 1948, when Wiener's book was published, generative grammars that form the formal theory created by Noam Chomsky was developed in the field of humanities, specifically linguistics, and the important notion of physics called $\delta$-Dirac's was used for the content interpretation of social processes ([19], p. 107). All this testifies to the fact that sciences about so-called soft structures may soon be represented by formal models, and not only by using in them some mathematical structures or just individual concepts. After all, it is difficult to say now what the formal models and what their nature will be. In addition, what is at stake here is the language of science, its conceptual system formally understandable for some sciences (psychology, linguistics, sociology), as well as for those that have long expressed their processes formally (physics, chemistry and others). Jean Piaget took a very clear voice on this topic ([17], p. 121-126).
} 
diversity comparable to the diversity of the surrounding reality; the work presents several - different in formal (measurable or content) terms - examples of risk estimation methods, with a predominance of statistical measures. Referring to the knowledge and examples taken from various fields of science, the authors of the paper want to confirm the hypothesis about risk as a category of a complex character, adequate to the diversity of the surrounding reality, hence a category difficult to capture with a homogeneous conceptual system of modern science, and even more with one language of science. One could say that science knows this, so why re-address this problem? Scientific paradigms, i.e., views of science on the methods of their application, change in practice and this is why this problem should be constantly dealt with.

\section{Strategic risk}

One of the most representative fields of knowledge concerning decision-making is game theory. Generally, all games tend to be controversial. Therefore, concerning the game theory, the question about the correct approach, in the formal dimension, of applying the strategy by players, is justified. When presenting the problem in a purely marginal dimension, i.e., expressing it in the language of topology, the point is when the game takes extreme values ( 0 or 1$)$ from the set of its options for strategy selection, and when these values are from the inside of the set, i.e., expressed by probabilities - numbers greater than zero and smaller than one (mixed strategies) ([5], p. 20). Generally understood, risk values belong to the closed set $I=[0,1]$. Therefore, in game theory, a risk matrix can be used instead of a pay-off matrix concerning optimal decisions. The risk category in the case of a two-person zero-sum game against Nature is the most sensible in terms of content, which is why Table 1 depicts the appropriate form of a pay-off matrix for such a game.

Table 1. The payoff matrix of a two-person (players) zero-sum game against Nature

\begin{tabular}{|c|c|c|}
\hline$G_{1} \backslash$ Nature & $w_{1}$ & $w_{2}$ \\
\hline$\alpha_{1}$ & 0 & 100 \\
\hline$\alpha_{2}$ & 1 & 1 \\
\hline
\end{tabular}

In the case when, instead of Nature, a player is a person who behaves rationally, then the above game has a saddle point in $\left(\alpha_{2}, w_{1}\right)$ with the value of $v=1$. However, Nature does not have to behave as a man wants. It has its preferences to choose individual strategies (natural ones). Therefore, concerning the tendencies of Nature, there is no point in accepting assumptions about its preferences from a human point of view, i.e., a player behaving rationally. Nonetheless, the game clearly defines pay-offs for both parties. When analysing them, one can see that the strategy $\alpha_{1}$ is better for the player $G_{1}$ 
than the strategy $\alpha_{2}$, because when choosing the first strategy a pay-off worth 100 is obtainable, and when taking the second one - only 1. Thus, it is legitimate to say that in games against Nature, especially when pay-offs are so varied, one should give up the principle of choosing the maximin strategy, and when selecting the optimal strategy, take a certain risk, i.e., accept so-called the principle of minimax risk ${ }^{6}$. The principle is that for every possible state of Nature $w_{i}$, the player $G_{1}$ determines the magnitude of the risk with its strategies. Concerning the given game, the player $G_{1}$ (i.e., us) does not risk anything concerning the chosen strategy $\alpha_{2}$, since always, both in the conditions $w_{1}$ and $w_{2}$, he wins (gets) just one. The second situation lies in the choice of strategy $\alpha_{1}$. Under the conditions $w_{1}$, the risk concerns the loss of the pay-off in the amount of 1 . On the other hand, in the conditions $w_{2}$ the loss is as much as 99 . Based on the analysis, a risk matrix for the first player was built in the form presented in Table 2 .

Table 2. The form of the risk matrix for the player $G_{1}$

\begin{tabular}{|c|c|c|}
\hline$G_{1} \backslash$ Nature & $w_{1}$ & $w_{2}$ \\
\hline$\alpha_{1}$ & 1 & 0 \\
\hline$\alpha_{2}$ & 0 & 99 \\
\hline
\end{tabular}

Compiling both tables and then conducting their content analysis concerning payoffs lead to the following conclusions: the player $G_{1}$, wanting to incur as little losses as possible, must apply the minimax strategy, which consists in choosing the matrix row, the largest element of which is the smallest possible value in terms of risk (the risk of loss of 1 is significantly greater than the risk of loss of up to 99). The presented method of analysis allows the statement, concerning the obtained risk matrix (Table 2), that the strategy $\alpha_{1}$ is optimal for the player $G_{1}$, which is consistent with the intuition and the choice made for the output matrix ${ }^{7}$.

What does the solution to such a game mean in terms of quantity and content, i.e., in both dimensions of interpretation, in other words, what is its role in the real process? The conclusion is quite simple: both approaches to the game matrix need to be analysed, which reduces the risk of making a bad decision.

\footnotetext{
${ }^{6}$ Savage introduces the outlined principle already in 1951. See: ([12], p. 173).

${ }^{7}$ The acceptance of such diversified elements in the matrix of pay-offs was intended to emphasise the role of risk in making decisions, without a clearly defined probability distribution for the conditions of Nature. In decisional practice, pay-offs do not always vary so significantly, however, the risk assessment related to making a decision is also a risk. In psychological terms (in the ideal dimension), when it comes to making decisions in risk conditions, people are divided into three groups. They are those who always take risks, those who never take risks and, finally, those for whom the risk is neutral (indifferent). In decision-making practice, however, this principle is fuzzy and in the sense of the definition of the concept of fuzziness [21]. This is why the fuzziness of the process is the most difficult to grasp with regard to decisionmaking processes, in the sense of accurate identification of these decisions.
} 
It was signalled in the introduction of the article that the risk has a diversified dimension. In the decision-making theory related to the credibility of decisions taken, more general statistical tools than those presented so far should be used. The following sections present formal methods recommended to apply when making different types of decisions.

\section{Risk of fraction estimation}

The fraction is the incidence of a certain event, e.g., the use of strategy in the two-person zero-sum game against Nature discussed above. The problem of fraction estimation should be considered on a statistical sample. In the case of a large sample, practically everything is settled based on the Lindeberg-Lévy theorem and other related to the fraction of central limit theorems.

Recently, more and more often attention has been paid to the fact that a normal distribution can also transform into a different distribution, then the use of a central theorem is questionable. The indicated problems are discussed in the framework of fractal statistics ([16], p. 107).

Assuming that $m$ is a statistic in the form of the number of distinguished elements (successes) in a randomly selected sample, and $\hat{p}$ means the fraction (percentage) representing the distinguished elements, the following relation is obtained:

$$
\hat{p}=\frac{m}{n}
$$

The statistics $\hat{p}$ takes the values:

$$
0=\frac{0}{n}, \frac{1}{n}, \frac{2}{n}, \ldots, \frac{n}{n}=1
$$

Numbers $0,1,2, \ldots, n$ are values from the statistics $m$ with the binominal distribution $^{8}$ (Bernoulli), hence:

$$
P\left(\frac{m}{n}=\frac{k}{n}\right)=P(m=k)=\left(\begin{array}{l}
n \\
k
\end{array}\right) p^{k} q^{n-k}
$$

${ }^{8}$ In the Bernoulli distribution, the number of successes is usually marked with the letter $k$. 
The probability value obtained with the use of the presented models may be quite satisfactory in some situation ${ }^{9}$. However, it happens that during calculation certain probabilities can be applied as existing side information - additional one. In this way, the risk of making an error for the estimated fraction of highlighted elements is significantly reduced, which is especially important when the statistical sample is small.

\section{Risk assessment in Bayesian terms}

The method of risk determination related to decisions taken in economically important areas such as marketing - sales volume of average company products and logistics - distribution of products to individual regions of the country, or finally to the whole economy management of a given region in the continental and even global sense has been presented in the subsequent section ${ }^{10}$.

When estimating the fraction using formula (1), all available information regarding the functioning of the process for the previous period over many weeks, months and even years is omitted. What is needed is, therefore, a formula that would give a $w$ weight in direct information and weight $(1-w)$ in the case of side information.

The formula below must be used for this purpose:

$$
O=w \frac{x}{n}+(1-w) \bar{p}
$$

where $x$ is the observed number of successes (prosperities) for $n$ experiments, while $w$ is given by the formula ${ }^{11}$ :

${ }^{9} \mathrm{The}$ problem of the risk of fraction estimation is presented on the example of the industrial sector, in which $20 \%$ of enterprises are additionally involved in export production. $N=20$ plants were randomly selected from among all enterprises in the industry. It was necessary to estimate the probability that the selected statistical sample includes at least $5 \%$ of enterprises producing goods also for export. Analytical calculations for the example were as follows:

$$
\begin{aligned}
& P\left(\frac{m}{n} \leq 0.05\right)=P(m \leq n \times 0.05)=P\left(m \leq 20 \times \frac{5}{100}\right)=P(m=0)+P(m=1) \\
& =\left(\begin{array}{c}
20 \\
0
\end{array}\right) \times\left(\frac{2}{10}\right)^{0} \times\left(\frac{8}{10}\right)^{20}+\left(\begin{array}{c}
20 \\
1
\end{array}\right) \times\left(\frac{2}{10}\right)^{1} \times\left(\frac{8}{10}\right)^{19}=0.012+0.057=0.069 \approx 0.07
\end{aligned}
$$

which means that the probability of finding at least $5 \%$ of enterprises producing goods also for export in a random sample is $7 \%$.

${ }^{10}$ Compare political concepts related to the global economy management.

${ }^{11}$ The formula for $w$ is obtained from the condition that on average the error square of this kind of estimation is to be as small as possible. 


$$
w=\frac{n}{n+\frac{\bar{p}(1-\bar{p})}{\sigma_{p}^{2}}-1}
$$

As regards the presented method, it should be borne in mind that if the process changes significantly from day to day, then one should not pay more attention to side information. However, if the process is stabilised, more attention should be given to the information about the course of the process related to the past ${ }^{12}$. The presented interpretation brings relevant information to the issue of the correct assessment of the fraction size, whereby everything in the assessment of the risk size of the decision being made is finally closed.

\section{Bayesian methods for estimating population distribution parameters}

The form of the weight $w$ of the Bayesian estimation depends on the nature of the problem under investigation and can be expressed, as in the previous point, as a fraction,

\footnotetext{
${ }^{12}$ The content example of the discussed issue is as follows. In the production plant under examination, the production of one department manufacturing a specific element for a computer was subject to constant, daily control, consisting in obtaining a statistical sample of $n=200$ pieces of the product. Throughout a long period, the process of producing the element gave $80 \%$ of good production and $20 \%$ of rejects, the variability of the fraction of rejects was characterised by the standard deviation of 0.04 .

One day, a sample with a constant number of two hundred elements of the product contained $x=80$ rejects. When estimating the fraction of rejects for the production of the whole day on the basis of the formula (1): $\hat{p}=\frac{x}{n}=\frac{80}{200}=\frac{40}{100}=0.40$ ? Then, all available information would be omitted. When putting the values $x=80, n=200, \bar{p}=0.2$ and $\sigma_{p}=0.04$ into formula (4), we obtain $w=\frac{200}{200+\frac{0.20 \times 0.80}{(0.04)^{2}}-1}=0.67$, in turn from formula (3), the estimated fraction of rejects related to the production of a given day amounted to $O=0.67 \times \frac{80}{200}+(1-0.67) \times 0.20=0.31$.

Using formula (3), the weight was given in direct information. In this case of the fraction of value $\hat{p}=0.40$ and weight in the side information, the fraction of rejects observed over a longer period of time was 0.20 . The average fraction of rejects observed in the past time was marked as $\bar{p}$ and the standard deviation measuring changes in the real fraction of rejects from day to days $\sigma_{p}$. When analysing the results obtained, it should be noted that the estimation value is more cautious than the estimation based only on direct information and in the sense that it contains about one third of the total weight of information regarding the course of the past production process, since: $1-0.67=0.33$, thus: $O=0.31<\hat{p}=0.40$.
} 
i.e., a certain scalar with the discrete distribution studied, more or less deeply in the sense of content interpretation.

In this part of the work, the attention is focused on reasoning related to the estimation of the average $m$ of the studied population (or any other distribution parameter of the studied population necessary to be calculated), understood as a random variable, not as a distribution parameter. The basic Bayesian methods for the indicated reasoning are quoted. The Bayesian methods have developed due to the introduction of the concept of the subjective (personal) probability ${ }^{13}$. They find application in marketing, in insurance, when setting rates, and in the broadly understood field of decision-making in conditions of uncertainty and risk.

For the present work, the method for determining the assessments (estimates) of parameters or risks is important, therefore the issue is considered more from the practical than the theoretical (operational) standpoint. When making decisions under conditions of uncertainty, it is necessary to assess the risk, e.g., when determining the expected losses of an insurance company. When a new risk insurance policy is concluded for the first time, the expected losses (compensation payments) are assessed solely from side information based on historical data ${ }^{14}$. Over the years, direct information is collected, based on which the insurance company may attempt to undertake a new risk assessment (of a building or car park) and adjust the insurance premium accordingly. Therefore, to estimate the risk for a given class of objects, two types of information and an appropriate analytical formula are indispensable ${ }^{15}$.

${ }^{13}$ Supporters of the subjective approach to probability define themselves as Bayesian statisticians. See, e.g.: ([4], p. 226).

${ }^{14}$ For example, when an insurance company concludes a fire insurance policy for a large office building or department store, the estimation of expected losses relies entirely on previous experience with similar risks, i.e., for other buildings of the same type. Similarly, when a company issues an insurance policy for (transported goods) freight transported by trucks belonging to a newly established department store, the loss estimates are also based on data obtained for other similar department stores.

${ }^{15}$ The issue is discussed on the example of an insurance company which insured five lorries delivering goods to a certain department store.

It is obvious that this specific risk (trucks and goods) of the given department store should correspond to the amount of losses (pay-offs), which the potential cars and transported goods may suffer in potential accidents.

The statistical analysis of the formulated task consists in taking into account the various types of risk, i.e., different, but similar to those of a new department store, machine parks operated by other department stores (i.e,. composed of, for example, 5 trucks), where it can be predicted that the average annual losses for individual parks will be different. The observed variation in values is influenced, among others, by the size of the area served, car equipment, or driver qualifications. The annual losses will therefore have a certain distribution, whose average and standard deviation should be marked by $\bar{m}$ and $\sigma_{m}$. It should be noted that $\bar{m}$ as an average loss for various similar car parks, gives the estimate of expected losses based entirely on side information.

In order to estimate the expected losses for a given car fleet based on direct and indirect information, one should find a certain compromise between average losses $\bar{x}$ actually incurred within a certain number of years (periods) and the original estimation $\bar{m}$ based on side data. 
One of various possibilities consists in adopting the weighted average of the form:

$$
O=w \bar{x}+(1-w) \bar{m}
$$

where $w$ is the percentage of weight (relative importance weight). The indicator $w$, as a percentage measure, takes values from 0 to $1^{16}$.

The numerical value gained by the weight $w$ depends on the quantity and quality of the direct and side information available to a decision-maker. The decision expressed in formula (5) is taken in the conditions of uncertainty, i.e., being in the area of the random variable of the analysed statistical parameter.

If the condition that, on average, the error square of the estimation is to be as small as possible, it can be proved that the formula for the weight $w$ will take the following analytical form:

$$
w=\frac{n}{n+\frac{\sigma^{2}}{\sigma_{m}^{2}}}
$$

where, following the marks, $\sigma$ is used to measure the variability of the random variable $X$ for the studied phenomenon, $\sigma_{m}$ is, in turn, the variability between the average values determined for comparable types of risk, $n$ is the number of observations ${ }^{17}$.

\footnotetext{
${ }^{16}$ If, for example, $w=15 \%$, this means that $15 \%$ of the total weight has been given the value $\bar{x}$ and $85 \%$ has been assigned to $\bar{m}$.

${ }^{17}$ The method of risk estimation using Bayesian methods is presented in the above-mentioned example of the insurance company: based on long-term data collected on trucks from many different department stores, it was assumed that for a park of 5 cars, annual losses of $\$ 1568$ with a standard deviation of $\$ 240$ may be expected. Using the same data but for the specific fleet of 5 trucks, the volatility of annual losses can be measured using a standard deviation of $\$ 385$. Substituting the values of $m=1565, \sigma_{m}=240$ and $\sigma=385$ to formula (6) allow obtaining $w=\frac{n}{n+\frac{385^{2}}{240^{2}}}=\frac{n}{n+2.57}$.

Analysing, for example, three periods (e.g., as years) the weight $w$ will reach the level of 0.54 , in the case of $n=10, w$ will be of 0.80 , which means that after 3 years the direct information covers $54 \%$ of the weight, and after 10 years until $80 \%$. It is completely consistent with the intuition that newer information is more important than the older one, and due to the presented calculation procedure, a quantitative result can be given, namely how many percent newer information is more important than older information.

Assuming, in turn, that within 3 years of validity of the policy, the insurance company incurred annual losses in the amounts of $\$: 1500,1950$, and 750 , after substituting to formula (5), the expected annual loss is estimated at $O=0.54 \times 1400+0.46 \times 1568=1477$, while the average of the sample would give a lower score of only $\$ 1.400=((1500+1950+750) / 3)$.
} 
The presented method can be recommended for use in all (any) situations in which good enough values $\bar{m}, \sigma$ and $\sigma_{m}$ can be obtained. It should be emphasised that no assumptions are required, in particular assumptions about the population from which a statistical sample is taken; also, assumptions regarding the distribution $m$ (more generally the population parameter studied). However, the situation is different when it comes to assessing the advantages of this type of estimation concerning other such estimation methods. Then, it can be assumed, and sometimes it is an obligatory requirement, that the population from which a sample is taken as well as the size distribution $m$ can be approximated with high accuracy through normal distributions of averages $m$ and $\bar{m}$, and standard deviations $\sigma$ and $\sigma_{m}$.

\section{Risk of the value of the econometric model}

Another area of analysis covers the risk assessment related to the optimal use in the decision process of the linear equation of multiple regression obtained from the econometric analysis, taking the form

$$
\hat{Y}=a_{0}+a_{1} X_{1}+\cdots+a_{k} X_{k}
$$

In econometric practice, it is necessary to verify the obtained empirical equation (8) as an estimator of the objective equation of the studied process with the assumed linear form

$$
Y=\alpha_{0}+\alpha_{1} X_{1}+\cdots+\alpha_{k} X_{k}+\varepsilon
$$

where $\varepsilon$ is the so-called random factor, which has a fundamental influence on the obtained form of the equation (8), that is it affects the numerical values of its structural parameters $\alpha_{i}$, for $i=1,2, \ldots, k$. This issue is widely used in decision-making practice, but as a measure of compliance of the obtained equation, the value of the determination coefficient is given (not always right ${ }^{18}$ ).

There are many stages of verification of equation (8) of the model (9), in which different statistics and stochastic coefficients are used to assess the conformity of the obtained econometric model with reality ${ }^{19}$. The random variation coefficient defined as shown below is an important measure of conformity assessment:

\footnotetext{
${ }^{18}$ The numerical example is not given here, since attention is focused on what the coefficient of determination is in terms of content.

${ }^{19}$ For instance, the coefficient of determination, coefficient of convergence and other measures as, e.g., from fuzzy set theory [8].
} 


$$
V_{e}=\frac{S_{e}}{\bar{Y}} \times 100 \%
$$

where $S_{e}$ is the standard deviation of the model residues, and $\bar{Y}$ is the average of the sample of the studied variable defined as $Y$. In econometrics, it is assumed that if the coefficient of random variation does not exceed 5\%, the obtained equation can be used to predict or interpret the nature of the studied problem. Therefore, the coefficient of variation is a proper measure to assess the degree of risk of using in the practice of the obtained econometric equation ${ }^{20}$.

\section{Interest rate risk}

The complexity of the risk category manifests itself in the diversity (variety) of functioning measures, i.e., ways of expressing it, which, in turn, also results from the adopted estimation methods. The procedure for determining risk, which is obligatory on the finance level, is important in practice and somewhat different from the risk assessment methods presented so far. By investing money (especially one's own) in various securities, shares on the stock exchange and other assets, the investment risk is estimated based on the observation of their volatility over time. The monetary value (share) is the riskier, the greater its volatility. The variability in return rates of various securities observed over time may serve as an example. In this case variability, i.e., risk

${ }^{20} \mathrm{At}$ this point, the question may be asked why the coefficient of determination $R^{2}$ is not proposed as a risk measure. The coefficient of determination has no meaningful interpretation, when in the econometric equation there is no free word, and, moreover, the element of the coefficient of determination, i.e., the multiple correlation coefficient, obtained from a given statistical sample, has a standard beta distribution. The density distribution function of the probability of this distribution has the form

$f(X)=\frac{1}{B(p, q)} x^{p-1}(1-x)^{q-1}$ for $0 \leq x \leq 1$, where $p$ and $q$ are parameters with values of $p>0, q>0$.

The term beta distribution comes from the beta function known in the mathematical analysis:

$B(p, q)=\int_{0}^{1} x^{p-1}(1-x)^{q-1} d x=\frac{\Gamma(p) \Gamma(q)}{\Gamma(p+q)}$, where in turn the so-called gamma function relative to the $p$ (or $q$ ) parameter has the form: $\Gamma(p)=\int_{0}^{+\infty} x^{p-1} \mathrm{e}^{-x} d x<\infty$, for $x>0$ and $p>0$.

The expected value of the determination coefficient in the standard beta distribution is expressed by the formula $E\left(R_{w}\right)=\frac{p}{p+q}=\frac{k-1}{n-1}$, where $k$ represents the number of explanatory variables in the multiple regression model, and $n$ constitutes the size of the statistical sample. When both systems are close to each other in terms of numbers, then large values of this coefficient are often observed, although in reality the coefficient of determination can be statistically irrelevant, i.e., the zero hypothesis is true that $\rho_{2}=0$. 
is defined by a statistical measure in the form of variance, but in practice, a standard deviation is used ${ }^{21}$. The higher the value of the standard deviation, the greater the dispersion of all observations to the average. High dispersion values mean a high likelihood of significant fluctuations in the return rates, which implies a high risk for investing money in securities in such volatility conditions. However, a standard deviation may be a good measure only in the case of a random system. If the observations are correlated, i.e., the series is characterised by autocorrelation, the usefulness of the standard deviation as a measure of dispersion is limited.
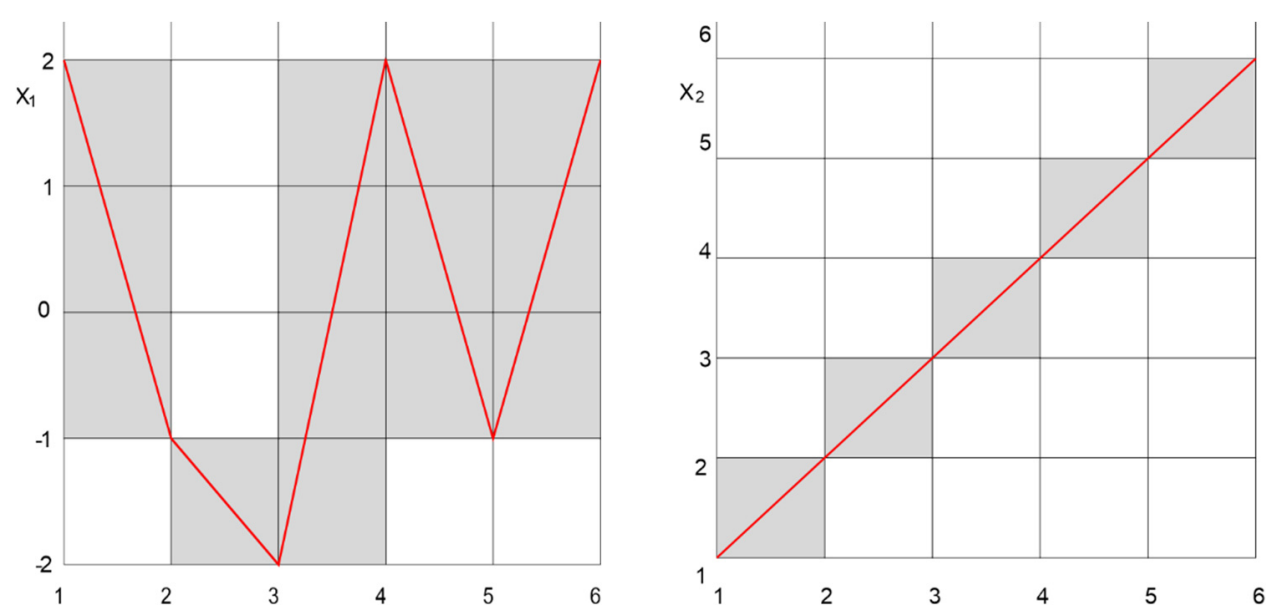

Fig. 1. Series $X_{1}$ (left) and $X_{2}$ (right) of return rates on investment in securities

When compared to the standard deviation, the fractal dimension is the measure that quantitatively well represents what differs the nature of processes in which time is the parameter ordering the observed results ${ }^{22}$.

\footnotetext{
${ }^{21}$ It is assumed that the action is the more risky, the greater its volatility $([13,16, \mathrm{p} .61)$.

${ }^{22} \mathrm{In}$ order to show the problem on an example, two series of return rates symbolically marked by $X_{1}$ and $X_{2}$ are presented. Values of observations in time and their basic characteristics are presented in the table
}

Table. Series $X_{1}$ and $X_{2}$ of return rates on investment in securities and their basic characteristics

\begin{tabular}{|c|c|c|c|c|c|c|c|c|c|}
\hline \multirow{2}{*}{ Series } & \multicolumn{4}{|c|}{ No. of observation } & Total return & Standard & $\begin{array}{c}\text { Fractal } \\
\text { rate [\%] }\end{array}$ & $\begin{array}{c}\text { deviation } \\
\text { dimension }\end{array}$ \\
\hline & 1 & 2 & 3 & 4 & 5 & 6 & & 1.42 \\
\hline$X_{1}$ & 2 & -1 & -2 & 2 & -1 & 2 & 1.93 & 1.70 & 1.13 \\
\hline$X_{2}$ & 1 & 2 & 3 & 4 & 5 & 6 & 22 & 1.71 & 1.13 \\
\hline
\end{tabular}

Source: the authors' study based on ([16], p. 62).

When analysing the presented values, it should be noted that the series $X_{2}$ has no normal distribution, but has a clear trend. In turn, in the series $X_{1}$ there is no trend and the folded rate of return is clearly lower 


\section{Banking risk}

Risk plays a significant role in economics and finance. The example of a quantitative risk assessment presented in the previous section concerned the economics of investing money, i.e., obtaining an answer to the question which shares are profitable. However, money - its surplus - can also be kept in a bank. Similarly, to the stock exchange, there is a risk of profit or loss in a bank, as it is an element of a market game subject to the competition of other banks, the aforementioned stock exchange and other market areas of money investing.

Bank managers who understand the bank as a market player strive to have as many depositors as possible. To achieve the assumed goal, the bank's assets and liabilities must be properly managed. Management, understood in the aspect of a financial process, in the case of a bank means minimising the risk of losses of various financial categories on the one hand, while maximizing profits from the entrusted savings on the other hand. From a commercial (market) point of view, a commercial bank is the same company as any other plant that manufactures products on the market to maximise profits. Therefore, it can be said that the management of a financial process in a bank is an activity in which an appropriate quantitative and qualitative structure of assets and liabilities that seemingly contradicts the balance sheet is aimed at.

The quantitative structure concerns the diversification of the loan and deposit portfolio. In turn, the quality of assets and liabilities includes interest rates (categories of loans and deposits, interest rates for both categories of assets, as three-month, oneyear, two-year, etc.). Properly shaped pages of the balance sheet enable a commercial bank to obtain the optimal financial result. The optimal financial result is understood as a potential profit, maximally possible to achieve in the given economic conditions.

Bank's profit is recognised in two two-component aspects: as an average profit and so-called volatile profit. An average profit is the obtained cash amount at the end of a reporting period (accounting period, for example, a month, a quarter, etc.) important for the bank. The mechanism of the asset and liability management process is inextricably linked to the monitoring of the profit volatility, i.e., controlling whether such a statistical parameter as the expected profit is a parameter in the discussed process or a random variable with a certain distribution (as discussed in the analysis of selected Bayesian methods). In practice, the difference in profits received from individual periods is the measure of the volatile profit. From a statistical point of view,

than in the series $X_{2}$. However, using only the standard deviation measure, it can be said that the risk of investing money in both types of shares is the same. Though, the estimated value of the fractal dimension contradicts the submitted conclusion, because for the shares $X_{2}$ it is smaller than for $X_{1}$, hence the graph $X_{1}$ will is more jagged than the graph $X_{2}$. In addition, the order has better memory than randomness and the series $X_{2}$ is ordered, while $X_{1}$ is chaotic. Based on Fig. 1 and the value of the fractal dimension, it is clearly visible that investing in $X_{2}$ is less risky than in $X_{1}$. 
the average value of a volatile profit by definition is unambiguously expressed as a random variable. This has a significant impact on the risk assessment on both sides of the balance sheet, i.e., liabilities and assets. Moreover, volatile profit is associated with a conceptual category, regarding the management of these two pillars of the bank's operations. Liabilities and assets form a globally analysed risk of a bank functioning, and a random variable of the uncertainty of profit ultimately determine the final profit. Therefore, asset and liability management is the process of monitoring numerous types of risk. The size of each risk category depends on the quantitative and qualitative structure of assets and liabilities adopted by a given bank. Liabilities and assets are the basic dimensions of the bank's operations. Finally, because profit depends on the structure of assets and liabilities, which implies the possibility of various types of risk, a profit is a function of the structure and individual risk categories. The structure of assets and liabilities and the risks associated with it form the core of the management and functioning of each commercial bank. In addition to the bank's assets and liabilities, the concept of banking risk is also associated with liquidity risk ${ }^{23}$, interest rate risk ${ }^{24}$, credit risk ${ }^{25}$, and currency risk $^{26}$. Theoretically, and in the practice of risk management, all types of risks can be effectively separated, i.e., they can also be treated independently from a statistical point of view. However, such statistical studies based on independence lead to far-reaching simplifications.

Different types of risk overlap, that is they interact with one another. Banking risk, therefore, creates a complex content and mathematical structure, which hinders its precise measurement ([7], p. 79-95). For this reason, individual countries and banks propose various measures of risk concerning its types. It is worth adding that the weight of the presented risk categories is not uniform. The most important role is attributed to credit risk. Individual asset categories are assigned $\mathrm{BIS}^{27}$ weights with the following values: $0 \%, 10 \%, \ldots, 50 \%$, and even $100 \%$. For example, $0 \%$ refers to cash, gold and other metals kept in a safe, while 50\% includes loans to mortgage buyers purchasing houses for housing purposes fully secured by mortgage [3]. Weights are assigned arbitrarily; besides, they may be changed in time, which takes place in reality. Why is it like that? The answer is quite simple in general logical dimension, as not only economics

\footnotetext{
${ }^{23}$ The liquidity risk is a banking risk occurring when there is not enough cash in the bank to cover cash liabilities towards depositors.

${ }^{24}$ The interest rate risk arises when changes in interest rates create a threat related to so-called mismatch positions that are sensitive to interest rate changes (for example, after the lowering of the interest rate, depositors may withdraw specific categories of their liabilities on a mass basis).

${ }^{25}$ The credit risk is a risk related to the inability of a borrower to meet his/her obligations to the bank.

${ }^{26}$ The currency risk occurs when changes in exchange rates can create a risk related to so-called open currency positions. Open currency positions are a consequence of currency transactions and are the difference between the value of assets and liabilities in a given foreign currency, while the difference is expressed in the national currency.

${ }^{27}$ Bank for International Settlements (BIS).
} 
but also mathematics is not able to clearly explain the complexity of all economic processes. In a sense, the problem boils down to the relationship between the nature of economic processes and the shaping of the value of money. Thus, the fact that Phoenicians invented and introduced money into the economic cycle, and ultimately to the whole dimension of human life, was not just a coincidence. This event was to a large extent the logical consequence of the existing economic complexity of the then world. The need arose to create a new exchange situation, since a new quality of socio-economic organisation appeared at that time, consisting of the risk of trade structure in the form of barter ${ }^{28}$, which necessitated the creation of a new quality of trade exchange in the form of determining the nominal value of the ore, which, in turn, would allow the value of one commodity to be converted into the value of any other commodity. This required a proper institution - an intermediary, that is what is called a bank today, and gold was the ore of exchange in that process. This need to introduce money (in the sense of economic complexity) can be easily explained using modern mathematics tools within the framework of which the utility of commodity bundles is analysed ${ }^{29}$.

The current studies, based on the history of financial results of banks, in recent decades particularly related to Western banks, since they were originally associated with the market economy, the conclusion is allowed that the management of assets and liabilities refers to the maximisation of profit in a short time, i.e., somehow independently of the bank's long-term policy. According to Bereza, the presented problem should be viewed differently, as the four types of risk mentioned above affect one another, they intermingle with one another and to some extent, this happens independently of the bank's policy. The main decision-maker is the market, the client of which is the bank [3]. Thus, these risks simply live their own lives, resulting from the complexity of the nature of the problem. Similarly, like the stock exchange, which does not always behave like the economy, now unable to fully manage these structures, creates it. The effects of risk should, therefore, be anticipated in both short and long terms. It might be asked which of the time horizons is more effective for minimising all kinds of risk. It seems that risk can be more effectively controlled within the framework of long-term policy. Therefore, among the relationships between assets and liabilities, one should also list those that are most general and, at the same time, most important. They are determined objectively through the process of customer behaviour concerning the surrounding conditions, i.e., they are related to the psychology of human behaviour [18]. It is about so-called bank rules ${ }^{30}$ : the golden banking rule ${ }^{31}$,

\footnotetext{
${ }^{28}$ Barter is the exchange of goods for goods.

${ }^{29}$ Commodity bundles ([15], p. 117).

${ }^{30}$ Banking rules are presented in chronological order, in other words, as they arose [10, 7].

${ }^{31}$ The golden banking rule states that with money that may be demanded at any time for repayment, only such operations can be made that can be withdrawn at any time to have cash for depositors. This rule cannot be applied formalistically (rigidly to the theory). In banking theory and practice, the banking rule is interpreted in a number of ways (for example, the term of payment of liabilities should correspond to the
} 
the core deposits rule ${ }^{32}$, the shift rule $\mathrm{e}^{33}$, and the maximum load rule $\mathrm{e}^{34}$. The rules are qualitative, but their observance allows minimising all types of banking risk. They have measurable consequences, among others, concerning the solvency category important for the bank, i.e., the bank's liability towards its clients.

In commercial banks, during the management of assets and liabilities, a measure called the capital adequacy ratio is used. This ratio, following the provisions of the Basel Committee on Banking Supervision, established in 1988 and its numerous subsequent modifications, is the relation between the capital and the balance sheet assets in a bank as well as off-balance sheet items, to which certain risk categories (expressed as a percentage) are assigned. The solvency ratio is one of the key economic parameters and, in addition to liquidity, is used to determine the financial condition of a bank; in other words, its size is proportionally related to the risk of the bad or good functioning of the bank.

The problems of estimating various types of banking risks presented so far have, in principle and to a large extent, a qualitative dimension. These risks also require quantitative assessments and thus is the use of tools from the field of complexity theory methods, stochastic methods, econometric methods, and forecasting. Only the two dimensions combined form the structure of the bank's operation, but through the risk category because randomness (the local range) is an essential element of the bank's operation. Therefore, in the next section, the attention is focused on participation in the risk assessment of the randomness of events.

relevant amounts and terms of assets). The first banking rule does not take into account new payments, the possibility of receiving funds on the money market (there is no consideration of daily and weekly money as part of interbank loans, etc.). Furthermore, even if a bank resigns from forward transactions, there is still a risk of non-repayment of loans on time (in practice, it is estimated that it is around $2 \%$ ). In commercial banks, the golden banking rule is used to set final repayment and payout deadlines and to control liquidity. Some argue that this is an abstract rule, as it assumes perfect compliance of the bank's liabilities with its assets in the sense of access to cash. However, it must be remembered that it is on the basis of this rule that the balance related to liabilities and assets of each bank is determined in the accounting process.

${ }^{32}$ The core deposit rule constitutes a modification of the golden banking rule. It included the possibility of prolonging deposits on accounts and the creation of new deposits that will replace the existing ones. Due to the core deposit rule, it becomes possible to transform the terms in a bank, which means that some of bank deposits - liabilities may be used beyond the dates of financial contributions in operations in favor of assets. These operations should be short-term so that they can be secured against loss, against the risk of deposit withdrawals by depositors in the event of possible economic turmoil.

${ }^{33}$ The shift rule - the third banking law is an explanation of what can be done in practice with core deposit money in contributions. The shift rule assumes that an active investment policy implemented as part of the bank's operations should be conducted in such a way that in the event of a clear liquidity tension, liquidation of assets before their contractually agreed payment date is possible without major losses, i.e., they should be as minimal as possible. The use the tools of econometrics and forecasting should be applied to assess their size (the risk of such a situation).

${ }^{34}$ The maximum load rule is the latter banking law. It assumes that the sum of losses due to premature termination of liabilities from the agreement (depositaries) cannot be greater than the amount of the bank's equity. 


\section{Risk and events}

The last simple and at the same time meaningful understanding of the type of risk measure quoted in the paper is the concept of the likelihood of the opposite event $(1-P(A))$ to the considered $P(A)$. The problem is that the probability of occurrence of the event $A$ must be known. However, it is often an uneasy matter. Probabilities need to be known and their value must not be assumed a priori. Exactly speaking, this problem is connected with knowledge about the event.

As based on the examples cited, it can be seen that each measure has a different character and content nature. The observed regularity results from the aforementioned complexity of Nature, and the specific measure of risk is only a consequence of the diversity of the significance of the problem being analysed.

Therefore, can risks and measures of its estimation be captured in a methodologically homogeneous operational and preferably algorithmic form? Risk is connected to uncertainty and probability. Probability distributions are potentially infinite and even the probability calculus does not know all of them, and when estimating the risk, one should use a specific probability distribution of the problem under investigation. The distribution can be well (theoretically) estimated based on a representative statistical sample, however, in practice, the calculation of the likelihood of the occurrence of events for many probability distributions is very difficult or laborious. If the statistical sample taken is sufficiently large, then the probability of the event of any probability distribution can be replaced by a normal distribution, which is a consequence of the Lindeberg-Lévy Central Theorem. However, following the achievements of science in recent decades, the main observation is that normal distribution is not the basis, as it was supposed - of mother nature. The normal distribution also changes into another form. The change depends on a certain coefficient $\alpha$ that assumes a value from the range $[0,2]$. For the value $\alpha=2$ and other parameters of the characteristic function of probability distributions with values $\beta=0, \gamma=1, \delta=1$ generalized by Lévy, the characteristic function of the normal distribution is obtained ([16], p. 107). This is a fundamental difference between the hypothesis expressed in market efficiency that $\alpha$ is always equal to 2 and the fractal market hypothesis that this coefficient may belong to the range [0,2]. This difference boils down to the fact that the change in the value $\alpha$ also essentially changes the nature of the time series, i.e., in principle the type of distribution.

\section{Conclusion}

The areas and examples of risk estimation cited in the text allow us to confirm the validity of the hypothesis set at the outset, in which the complex nature of the risk was assumed. The issue of risk is as wide as the reality is diverse, and therefore various 
methods and research tools are used to describe different dimensions of risk. Due to the heterogeneity of the risk categories, science lacks a uniform methodology to analyse this conceptual category, especially the overall algorithm of its estimation that is fundamental for the management.

Theoretically, there is nothing to prevent us from asking whether it is possible to create a uniform methodology for determining (defining) and then estimating, i.e., expressing risk in quantitative and qualitative form for all areas of science and life, in the same way. In other words, can the risk be put into a universal framework? Man, in his operation uses words and numbers, and risk is present in both of these conceptual categories. Specialists in quantitative methods value the numerical result more, and the proponents of the qualitative methods prefer the content interpretation of the obtained result. But can it be asked in both of these dimensions what each of these results means separately? A word belongs to the qualitative category and a number to the quantitative one.

Words and numbers are not independent of each other, and only together they form the dimension of a decision being made, although the weight of both dimensions in a particular case does not have to be equally important ${ }^{35}$. Referring again to the examples presented in the article, it can be assumed that the quantitative result obtained in the area of measurable risk analysed should be appropriately interpreted in qualitative terms (given its content interpretation). In the opposite direction, i.e., concerning the quality risk, the quantitative interpretation is also important, but sometimes it is artificially explicated since there is no proper measure of the quality to quantity ratio ${ }^{36}$. It may happen, as in the example related to the fractal dimension, that the received quantitative risk assessment is obtained from a wrong interpretation of the nature of the problem under investigation, which is defined as the results pulled out of thin air. Despite objective methodological difficulties, determining the level of risk in the decision-making process cannot be overestimated. Correctly made decisions translate into the quality of management. The acquired knowledge constitutes the basis for making right decisions. Knowledge eliminates or at least significantly reduces the element of uncertainty in the decision-making process. The value of the estimated risk ultimately constitutes a quantitative or qualitative measure of the decision. It enables checking the result: to

\footnotetext{
${ }^{35}$ Equally, it does not always mean that a division is just. In a comprehensive way, this problem is captured and solved by the theory of games of any sum, when there is a division, for example, of a hundred dollars between the poor and the rich ([15], p. 129, 130).

${ }^{36}$ In the scientific literature, attempts are made to translate quality into quantity, i.e., to express the content (meaning) through a number. The authors believe that such actions and operational procedures, from a methodological point of view, are sometimes carried out artificially, for the dimension of semantic space and its semantic metrics are dealt with linguistics and psychology. The mentioned sciences use formal methods and tools, but it does not mean that the nature of problems analysed in them is what the formal tools are used for.
} 
compare the reality with the forecast. However, there is one condition that such an estimate was taken. Therefore, at present, the problem of risk estimation should be viewed pragmatically, and in the time perspective also methodologically, and at the beginning at least theoretically, since based on the estimated risk value appropriate decisions are made, which implies appropriate effects of taking them.

\section{References}

[1] ARRow W., Essays in the Theory of Risk-Bearing, PWN, Warsaw 1979 (in Polish).

[2] AVEN T., Risk assessment and risk management. Review of recent advances on their foundation, Eur. J. Oper. Res., 2016, 253, 1-13.

[3] Bereza S., Banking Risk Management, Związek Banków Polskich, Warszawa 1992 (in Polish).

[4] Freund J.E., Modern Elementary Statistics, PWN, Warszawa 1968 (in Polish).

[5] Galanc T., KoŁWZan W., PieroneK J., Theoretical and methodological bases of threats. The method of security management support, Oper. Res. Dec., 2014, 24 (3), 5-21.

[6] Galanc T., KolwZan W., Pieronek J., SkowroneK-Grądziel A., Logic and risk as qualitative and quantitative dimensions of decision-making process. Oper. Res. Dec., 2016, 26 (3), 21-42.

[7] GŁadYsz B., KoŁWZAN W., MERCIK J., Factors of effective management of commercial bank assets and liabilities, [In:] Management, Financial Risk. Theory and Practice, Zeszyty Naukowe nr 5, Wyższa Szkoła Zarządzania i Finansów we Wrocławiu, Wrocław 2000, 79-95 (in Polish).

[8] GŁadysz B., KuchtA D., A method of variable selection for fuzzy regression - the possibility approach, Oper. Res. Dec., 2011, 21 (2), 5-15.

[9] IVANOv V., The asymmetry of the brain and sign systems, Sov. radio, Moscov 1978 (in Russian).

[10] JAWORSKI W.L., Banking. Basic Assumptions, Poltext, Warsaw 1993 (in Polish).

[11] JuChNOwICZ M., SieNKIEWICZ Ł., How to evaluate a job? Value of positions and competences, Difin, Warsaw 2006 (in Polish).

[12] Kofler E., Introduction to Game Theory, PZWS, Warsaw 1963 (in Polish).

[13] Markowitz H.M., Portfolio selection, J. Fin. 1952, 7, 77-91.

[14] Milewski T., Linguistics, PWN, Warsaw 1963 (in Polish).

[15] Owen G., Game Theory, PWN, Warsaw 1975 (in Polish).

[16] Peters E.E., Chaos Theory and Capital Markets, WIG-Press, Warsaw 1997 (in Polish).

[17] Piaget J., Psychology and Epistemology, PWN, Warsaw 1977 (in Polish).

[18] Plummer T., Forecasting Financial Markets, WIG-Press, Warsaw 1995 (in Polish).

[19] WoŁgIN L.N., Optimization, WNT, Warsaw 1970.

[20] Vose D., Risk Analysis. A Quantitative Guide, Wiley, 2008.

[21] ZADEH L.A., Fuzzy sets, Inf. Control, 1965, 8 (3), 338-353. 